\title{
Vitamin B12 deficiency and diabetic neuropathy in patients taking metformin: a cross-sectional study
}

\author{
Mauricio Alvarez ${ }^{1,2}$, Oswaldo Rincón Sierra ${ }^{3}$, Ginna Saavedra ${ }^{4}$ and Sergio Moreno ${ }^{5}$ \\ ${ }^{1}$ Endocrinology Program, Facultad de Medicina y Ciencias de la Salud, Universidad Militar Nueva Granada,Bogotá, Colombia \\ 2Endocrinology Department, Hospital Militar Central, Bogotá, Colombia \\ ${ }^{3}$ Endocrinology Department, Hospital Militar Central, Bogotá, Colombia \\ ${ }^{4}$ Investigation Department, Epidemiology, Hospital Militar Central, Bogotá, Colombia \\ ${ }^{5}$ Investigation Department, Statistics, Hospital Militar Central, Bogotá, Colombia
}

Correspondence should be addressed to M Alvarez: mauricioalvarez613@gmail.com

\begin{abstract}
Objective: Vitamin B12 deficiency resulting from metformin use has been demonstrated in multiple studies. In this study, we aimed to evaluate the prevalence of vitamin B12 deficiency in patients with chronic metformin use and the relationship between vitamin B12 deficiency and diabetic neuropathy.

Methods: A cross-sectional study was conducted with 162 patients. Vitamin B12 levels were measured by chemiluminescence immunoassay. Diabetic neuropathy was evaluated by patient record, nerve conduction and Michigan test for the diagnosis of diabetic neuropathy. Additional data, including demographic characteristics were collected. A linear regression model was used to evaluate variables that correlated with vitamin B12 levels and diabetic neuropathy.

Results: Low vitamin B12 levels were found in 7.3\% (95\% Cl: 4.0-12\%) of patients. In those with diabetic neuropathy, altered (low and borderline) vitamin B12 level was 64\% (95\% Cl: 47-78\%) compared to $17 \%(95 \% \mathrm{Cl}: 10-26 \%)$ in patients without diabetic neuropathy (coefficient: -110.8; Cl 95\%: -165.8, -59.7). Those taking a higher metformin dose had lower levels of vitamin B12 (coefficient: -0.061 ; Cl 95\%: $-0.09,-0.024)$. In addition, female patients had higher levels of vitamin B12 compared to men (coefficient: 49.1;

Cl 95\%: 2.3-95).

Conclusions: Vitamin B12 deficiency is highly prevalent, especially in patients with diabetic neuropathy. In this study an inverse correlation was found between diabetic neuropathy and the plasma level of vitamin B12. Higher doses of metformin and male sex were factors related to lower levels of vitamin $\mathrm{B} 12$.
\end{abstract}
Key Words
- vitamin B12
- metformin
- diabetes mellitus
- prediabetic state
- malabsorption
- syndromes
- diabetic neuropathies

\section{Introduction}

Vitamin B12 deficiency is a known adverse effect of chronic metformin use, which was first described by Berchtold et al. in 1969 (1) and has been demonstrated in several studies since then $(2,3,4)$. The prevalence of vitamin B12 deficiency in patients taking metformin varies from 5 to $40 \%$ across different populations $(2,3,4,5)$.
The mechanism by which vitamin B12 deficiency occurs in patients with chronic metformin use is unclear; however, proposed mechanisms include alteration of the motility of the small intestine with consequent bacterial overgrowth and inhibition of vitamin B12 intrinsic factor complex absorption. Since inhibition of the 
calcium-dependent absorption of the intrinsic factor, B12 complex at the ileum level has been demonstrated, competitive inhibition of vitamin B12 absorption and alterations of the intrinsic factor and cubilin (CUBN) receptor have also been proposed $(4,5,6)$.

Vitamin B12 deficiency is associated with multiple neurological and neurocognitive manifestations, including peripheral and autonomic neuropathy, combined subacute degeneration of the spinal cord, delirium, dementia, and axonal demyelination $(6,7)$. These neurological manifestations can be erroneously interpreted as manifestations of diabetic neuropathy in diabetic patients with chronic metformin use $(8,9,10)$.

The optimal diagnostic method for diabetic neuropathy in these patients is unknown; however, several alternatives are available with variable sensitivity and specificity, as electrodiagnostic studies have achieved higher sensitivity and specificity in the diagnosis of diabetic neuropathy $(11,12)$. One of the best known methods used in research is the diabetic neuropathy screening instrument of Michigan (13, 14, 15).

The American Diabetes Association guidelines now recommend routine evaluation for Vitamin B12 deficiency in patients taking metformin, as studies conducted in recent years have linked metformin use to diabetic neuropathy (16). Previously, the American College of Endocrinology had also recommended monitoring vitamin B12 levels in patients taking metformin (17).

In this study, we aimed to evaluate the prevalence of Vitamin B12 deficiency in patients with chronic metformin use and evaluate how it is related with diabetic neuropathy.

\section{Methodology}

A cross-sectional study was conducted to estimate the prevalence of vitamin B12 deficiency in patients with chronic metformin use and the prevalence of diabetic neuropathy in patients with normal and low vitamin B12 levels. Additional data, including demographic characteristics, were collected to evaluate the characteristics of patients with vitamin B12 deficiency and diabetic neuropathy. A linear regression model was used to evaluate variables that correlated with Vitamin B12 levels and the correlation between having altered vitamin B12 levels and the presence of diabetic neuropathy.

Clinical records of 162 patients who visited the endocrinology service of the Central Military Hospital during 2017 were reviewed. We retrospectively identified patients diagnosed with diabetes mellitus or prediabetes who were treated with metformin for more than 3 months. Vitamin B12 levels were measured by chemiluminescence immunoassay and evaluation for diabetic neuropathy was performed by any of the following: clinical records of nerve conduction study or by Michigan neuropathy screening instrument (MNSI).

Informed consent was given to apply the MNSI.

Inclusion criteria: adult patients with diabetes or prediabetes according to Standards of Medical Care in Diabetes Guidelines (16), in treatment with metformin for more than 3 months.

Exclusion criteria: Patients were excluded from the study if they had one or more of the following characteristics: previous gastrointestinal surgery or malabsorptive syndrome or if they were taking a vitamin B12 substitution or multivitamins with vitamin B12.

\section{Variables}

The following variables were collected: age, gender, time of diabetes diagnosis (months), time on metformin (months), dose of metformin (mg), vitamin B12 levels $(\mathrm{pg} / \mathrm{mL})$, previous diagnosis of diabetic neuropathy by clinical record, previous nerve conduction study or by MNSI.

Vitamin B12 levels were classified as low if they were less than $200 \mathrm{pg} / \mathrm{mL}$, borderline if they were between 200 and $300 \mathrm{pg} / \mathrm{mL}$, and normal if they were higher than $300 \mathrm{pg} / \mathrm{mL}$, taking into account that normal values are based on one of the largest studies derived from the Diabetes Prevention Program Outcomes Study but are not standardized (2).

The Michigan neuropathy screening instrument (MNSI) was used to clinically diagnose diabetic neuropathy. The test is administered by a symptomatic initial questionnaire and a physical examination component. The score's usefulness in the diagnosis of diabetic neuropathy has been validated by several studies $(11,12,13)$. If the initial questionnaire is positive, the second component of the test is performed. A cut-off point of 2 or more is used for the diagnosis of neuropathy; this range has shown a sensitivity of up to $80 \%$ and specificity of up to $95 \%$ (14).

\section{Statistical analysis}

A sample size of at least 126 patients was calculated for a margin of error of $7 \%(95 \% \mathrm{CI})$, with an estimated https://ec.bioscientifica.com https://doi.org/10.1530/EC-19-0382 (c) 2019 The authors Published by Bioscientifica Ltd
This work is licensed under a Creative Commons Attribution-NonCommercial-NoDerivatives 4.0 delnternationab ticense.ifica.com at 04/26/2023 09:23:12AM 
prevalence of $20 \%$. We used means, standard deviations, and percentages to describe the results. A linear regression model was used to evaluate the variables that correlate with vitamin B12 levels.

Of the 162 patients included in this study, it was possible to establish the presence or absence of diabetic neuropathy in 122 patients using clinical history, nerve conduction study or performing MNSI. The other 40 patients did not have information in the clinical history, and it was not possible to perform the MNSI.

The Spearman correlation coefficient was used to evaluate the relationship between the continuous variables of Vitamin B12 levels and metformin dose, time of metformin use, time of diagnosis of diabetes, and values of diagnostic instruments for diabetic neuropathy. The Wilcoxon and Mann-Whitney test was used to evaluate the relationship between vitamin B12 levels with gender and diagnosis of diabetic neuropathy. Nonnormally distributed variables were transformed to their natural logarithm. A $P<0.05$ was considered to be statistically significant.

\section{Ethical considerations}

The study was approved by the Ethical Committee of the Hospital Militar Central, Bogotá, Colombia.

\section{Results}

Overall, 162 patients were included in this study. There were 72 men (45\%) and 90 women (55\%) and the average age was 64 years. The average daily dose of metformin taken was $1536 \mathrm{mg}$ and the average time of metformin use was 108 months (Table 1).

Altered levels of vitamin B12 (borderline or low) were found in $29 \%$ of patients ( 47 cases; $95 \%$ CI: $22-36 \%$ ). The prevalence of borderline levels of Vitamin B12 was 20.9\%

Table 1 Participant demographic and clinical characteristics.

\begin{tabular}{lcc}
\hline Variable & $\boldsymbol{n = 1 6 2}$ \\
\cline { 1 - 2 } Age (years) & $64(12)$ \\
Female & $90(55 \%)$ \\
Vitamin B12 levels (pg/mL) & $410(154)$ \\
Metformin use time (months) & $108(90)$ \\
Metformin dose (mg) & $836(614)$ \\
Diagnosis time (years) & $35(21 \%)$ \\
Diabetic neuropathy & $5(4.1)$ \\
MNSI 1 & $4.7(2.6)$ \\
MNSI 2 & \\
\hline & \\
\hline https://ec.bioscientifica.com & Published by Bioscientifica Ltd \\
https://doi.org/10.1530/EC-19-0382 &
\end{tabular}

(34 cases; 95\% CI: $15-27 \%$ ) and the prevalence of low levels was 7.4\% (12 cases; 95\% CI: 4.0-11\%).

Nine men had low levels of Vitamin B12 (12\%; 95\% CI: 6-21\%) and 17 had borderline levels (23\%; 95\% CI: $15-34 \%)$; four women had low levels (4\%; 95\% CI: $1-10 \%)$ and 17 had borderline levels (18\%; 95\% CI: 12-28\%) (Table 2). Female patients had higher levels of Vitamin B12 compared to men (coefficient: 49.1; 95\% CI: 2.3-95).

In patients older than 70 years $(n=58)$, borderline levels of vitamin B12 were found in 13 patients (22\%; 95\% CI: 13-34\%) and low levels were found in seven patients (12\%; 95\% CI: 5-22\%). However, the coefficient of correlation between age and vitamin B12 levels was not statistically significant (coefficient: $-0.86 ; 95 \%$ CI: -2.7 , 1.0) (Table 3).

Metformin dose was significantly inversely associated with vitamin B12 levels (Coefficient: -0.06; CI 95\%: -0.10, -0.028). Length of metformin use was not significantly associated with vitamin B12 levels (Coefficient: 0.63; 95\% CI: $-0.36,1.64$ ) (Table 3).

\section{Diabetic neuropathy}

Of the 162 patients included in this study, it was possible to establish the presence or absence of diabetic neuropathy in 122 patients using clinical history, nerve conduction study or performing MNSI. In this group of 122 patients, 34 (27\%) were diagnosed with diabetic neuropathy.

The prevalence of altered vitamin B12 levels (low or borderline) in patients with diabetic neuropathy was $64 \%$ (95\% CI: 47-78\%). Low levels of vitamin B12 were found in eight patients (23\%; 95\% CI: $12-40 \%)$ and borderline levels were found in 14 patients (41\%; 95\% CI: $26-47 \%$ ); 12 patients had normal levels (35\%; 95\% CI: $21-52 \%$ ) (Table 4). Diagnosis of diabetic neuropathy was associated with lower levels of vitamin B12 (Coefficient: 116.9; 95\% CI: $-165.8,-68.0$ ) (Table 3).

Table 2 Vitamin B12 deficiency according to sex and age.

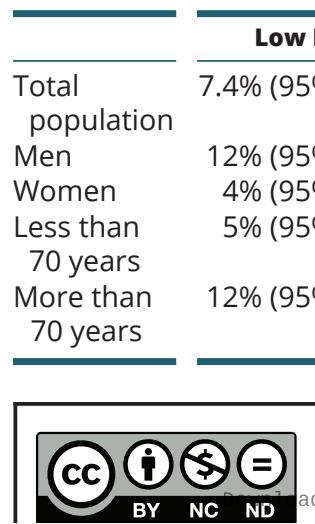

This work is licensed under a Creative Commons Attribution-NonCommercial-NoDerivatives 4.0 Internationab ticense.ifica.com at 04/26/2023 09:23:12AM 
Table 3 Linear regression: factors related to low levels of vitamin B12.

\begin{tabular}{|c|c|c|}
\hline & \multicolumn{2}{|r|}{ Model A } \\
\hline & Coefficient & $95 \% \mathrm{Cl}$ \\
\hline Metformin dose & -0.06 & $-0.10,-0.028$ \\
\hline Gender (female) & 49.1 & 2.3-95.8 \\
\hline Diabetic neuropathy & -116.9 & $-165.8,-68.0$ \\
\hline Age & -0.86 & $-2.7,1.0$ \\
\hline Time from diagnosis & -5.2 & $-16.8,6.3$ \\
\hline Time on metformin & 0.63 & $-0.36,1.64$ \\
\hline
\end{tabular}

\section{Discussion}

This study suggests that vitamin B12 deficiency is highly prevalent in our population ( $7 \%$ of patients); however, it is not as high as described in some recent studies showing prevalence from 28 to $41 \%(18,19,20,21)$. A recently published meta-analysis found that the use of metformin is a risk factor for vitamin B12 deficiency in diabetic patients (22). Previous studies have indicated prevalence rates of vitamin B12 deficiency ranging from 5 to $40 \%$; however, the cut-off points have been arbitrary defined. The results of this study are similar to the studies that take equivalent cut-off points $(2,4)$.

We found that male patients, those taking higher doses of metformin, and patients with diabetic neuropathy have significantly lower levels of vitamin B12 and a higher prevalence of low or borderline levels of vitamin B12. A higher dose of metformin was associated with lower levels of vitamin B12, which has been described in previous studies $(4,5,23,24)$.

The prevalence of diabetic neuropathy on our population ( $27 \%$ of patients) was lower than that described in previous studies that have found a prevalence of diabetic neuropathy of $39-50 \%$ of the diabetic population $(25,26)$. Interestingly, we found a significant correlation between having lower levels of vitamin B12 and having a positive diagnosis of diabetic neuropathy. We also found a high prevalence of low levels of vitamin B12 in patients with diabetic neuropathy (17\% of patients) and an even more high prevalence of altered levels of vitamin B12 (64\% of patients with diabetic neuropathy had low or borderline levels of vitamin B12).

Table 4 Diabetic neuropathy according to vitamin B12 levels.

\begin{tabular}{|c|c|c|c|}
\hline \multirow{2}{*}{$\begin{array}{l}\text { Vitamin } \\
\text { B12 level }\end{array}$} & \multicolumn{3}{|c|}{ Diabetic neuropathy } \\
\hline & Present & Absent & Total \\
\hline Low & 8 (23\%; 95\% Cl: 12-40\%) & $4(77 \%)$ & $12(100 \%)$ \\
\hline Borderline & 14 (41\%; 95\% Cl: 26-47\%) & $11(59 \%)$ & $25(100 \%)$ \\
\hline Normal & 12 (35\%; 95\% Cl: 21-52\%) & $72(65 \%)$ & $84(100 \%)$ \\
\hline
\end{tabular}

\begin{tabular}{|c|c|c|}
\hline \multicolumn{3}{|c|}{ Model B } \\
\hline Coefficient & $95 \% \mathrm{Cl}$ & $P$ value \\
\hline-0.061 & $-0.09,-0.024$ & 0.001 \\
\hline 54.7 & $9.0-100.4$ & 0.019 \\
\hline-110.8 & $-162.0,-59.7$ & 0.000 \\
\hline- & - & - \\
\hline- & - & - \\
\hline - & - & - \\
\hline
\end{tabular}

Previous studies have been published to find a correlation between diabetic neuropathy and vitamin B12 deficiency, but they are descriptive studies and have not been conclusive $(8,27,28,29,30$,). Gupta et al. (27) found a positive correlation between metformin use time and diabetic neuropathy and a negative correlation between metformin use time and vitamin B12 levels. In a systematic review by Sun et al. (29) vitamin B12 and methyl cobalamin supplementation had beneficial effects on symptoms of neuropathy such as pain and paresthesia but electrophysiological measures were not consistent.

Recently a meta-analysis did not find enough evidence to associate diabetic neuropathy and vitamin B12 deficiency, but there are not enough quality studies to obtain conclusive results (22). Another study in which vitamin B12 supplementation was performed in patients with diabetic neuropathy found no conclusive evidence regarding improvement of neuropathy symptoms (31). Interestingly, folic acid supplementation does appear to have a positive effect on diabetic neuropathy according to a recent study (32).

Unlike previous studies, we found a significant difference in vitamin B12 levels in male patients. This finding is important, considering that diabetic neuropathy is also more prevalent in males; however, no physiological explanation was identified for these results. Most studies do not describe the differences between vitamin B12 deficiency according to sex. We found a single study that showed a higher prevalence of vitamin B12 deficiency in women (28). Another study found that being black was a protective factor for vitamin B12 deficiency (21). We do not know the reason why in our population there was a significant difference in men with vitamin B12 deficiency, it is probably due to the fact that the male population was older than the female population. However, we do not rule out other additional predisposition in male patients for lower vitamin B12 levels and diabetic neuropathy.

Since diabetes is highly prevalent and the first line of pharmacological management is metformin, it is important to investigate a frequent complication of this 
treatment, vitamin B12 deficiency, which aggravates multiple complications of diabetes. The population at risk of vitamin B12 deficiency induced by metformin is very high and, according to the results of this study, screening for vitamin B12 deficiency is justified, especially in groups at higher risk, such as people with diabetic neuropathy receiving high doses of metformin.

\section{Limitations}

Diagnosis of diabetic neuropathy was performed heterogeneously through clinical history from clinical or electrophysiological evaluation or based on the MNSI, methods with varying degrees of sensitivity and specificity that can alter the reliability of the diagnosis of neuropathy in some cases; however, the bias of the latter method applies to low, borderline, and normal vitamin B12 groups. Additionally, we do not know how many of the patients had neuropathy prior to the start of treatment with metformin, a bias that applies to all patients. The methodology of this study did not permit the ability to establish a causal association between vitamin B12 deficiency and diabetic neuropathy.

\section{Conclusion}

Vitamin B12 deficiency is highly prevalent, especially in patients with diabetic neuropathy. In this study an inverse correlation was found between diabetic neuropathy and the plasma level of vitamin B12. Higher doses of metformin and male sex were factors related to lower levels of vitamin B12. Therefore, Vitamin B12 levels should be monitored in patients taking metformin chronically, especially in patients with diabetic neuropathy.

The association between diabetic neuropathy and Vitamin B12 deficiency is of great importance, since diabetic or prediabetic patients diagnosed with diabetic neuropathy may have neuropathy due to vitamin B12 deficiency. Thus, this condition should be ruled out before initiating diabetic neuropathy treatment.

\section{Declaration of interest}

The authors declare that there is no conflict of interest that could be perceived as prejudicing the impartiality of the research reported.

\section{Funding}

This work did not receive any specific grant from any funding agency in the public, commercial, or not-for-profit sector.

\section{References}

1 Berchtold P, Bolli P, Arbenz U \& Keiser G. Disturbance of intestinal absorption following metformin therapy (observations on the mode of action of biguanides) [in German]. Diabetologia 19695 405-412. (https://doi.org/10.1007/bf00427979)

2 Aroda VR, Edelstein SL, Goldberg RB, Knowler WC, Marcovina SM, Orchard TJ, Bray GA, Schade DS, Temprosa MG, White NH, et al. Long-term metformin use and vitamin B12 deficiency in the diabetes prevention program outcomes study. Journal of Clinical Endocrinology and Metabolism 2016101 1754-1761. (https://doi.org/10.1210/ jc.2015-3754)

3 Reinstatler L, Qi YP, Williamson RS, Garn JV \& Oakley GP Jr Association of biochemical $B_{12}$ deficiency with metformin therapy and vitamin $B_{12}$ supplements: the National Health and Nutrition Examination Survey, 1999-2006. Diabetes Care 201235 327-333. (https://doi.org/10.2337/dc11-1582)

4 Ko SH, Ko SH, Ahn YB, Song KH, Han KD, Park YM, Ko SH \& Kim HS. Association of vitamin B12 deficiency and metformin use in patients with type 2 diabetes. Journal of Korean Medical Science 2014 29 965-972. (https://doi.org/10.3346/jkms.2014.29.7.965)

5 de Jager J, Kooy A, Lehert P, Wulffelé MG, van der Kolk J, Bets D, Verburg J, Donker AJ \& Stehouwer CD. Long term treatment with metformin in patients with type 2 diabetes and risk of vitamin B-12deficiency: randomised placebo controlled trial. BMJ 2010340 c2181. (https://doi.org/10.1136/bmj.c2181)

6 Kibirige D \& Mwebaze R. Vitamin B12 deficiency among patients with diabetes mellitus: is routine screening and supplementation justified? Journal of Diabetes and Metabolic Disorders 20131217. (https://doi.org/10.1186/2251-6581-12-17)

7 Hannibal L, Lysne V, Bjørke-Monsen AL, Behringer S, Grünert SC, Spiekerkoetter U, Jacobsen DW \& Blom HJ. Biomarkers and algorithms for the diagnosis of vitamin B12 deficiency. Frontiers in Molecular Biosciences 20163 27. (https://doi.org/10.3389/ fmolb.2016.00027)

8 Roy RP, Ghosh K, Ghosh M, Acharyya A, Bhattacharya A, Pal M, Chakraborty S \& Sengupta N. Study of vitamin B12 deficiency and peripheral neuropathy in metformin treated early type 2 diabetes mellitus. Indian Journal of Endocrinology \& Metabolism 201620 631-637. (https://doi.org/10.4103/2230-8210.190542)

9 Bells DS. Metformin-induced vitamin B12 deficiency presenting as a peripheral neuropathy. Southern Medical Journal 2010103 265-267. (https://doi.org/10.1097/SMJ.0b013e3181ce0e4d)

10 Rodríguez-Gutiérrez R, Montes-Villarreal J, Rodríguez-Velver KV, González-Velázquez C, Salcido-Montenegro A, Elizondo-Plazas A \& González-González JG. Metformin use and vitamin B12 deficiency: untangling the association. American Journal of the Medical Sciences 2017354 165-171. (https://doi.org/10.1016/j.amjms.2017.04.010)

11 Fateh HR, Madani SP, Heshmat R \& Larijani B. Correlation of Michigan neuropathy screening instrument, United Kingdom screening test and electrodiagnosis for early detection of diabetic peripheral neuropathy. Journal of Diabetes and Metabolic Disorders 201515 8. (https://doi.org/10.1186/s40200-016-0229-7)

12 Moghtaderi A, Bakhshipour A \& Rashidi H. Validation of Michigan neuropathy screening instrument for diabetic peripheral neuropathy. Clinical Neurology and Neurosurgery 2006108 477-481. (https://doi. org/10.1016/j.clineuro.2005.08.003)

13 Ticse R, Pimentel R, Mazzeti P \& Villena J. Elevada frecuencia de neuropatía periférica en pacientes con diabetes mellitus tipo 2 de un hospital general de Lima-Perú. Revista Medica Herediana 201324 114-121. (https://doi.org/10.20453/rmh.v24i2.593)

14 Feldman EL, Stevens MJ, Thomas PK, Brown MB, Canal N \& Greene DA. A practical two-step quantitative clinical and electrophysiological assessment for the diagnosis and staging of diabetic neuropathy. Diabetes Care 199417 1281-1289. (https://doi. org/10.2337/diacare.17.11.1281) 
15 Baraz S, Zarea K, Shahbazian HB \& Latifi SM. Comparison of the accuracy of monofilament testing at various points of feet in peripheral diabetic neuropathy screening. Journal of Diabetes and Metabolic Disorders 201413 19. (https://doi.org/10.1186/2251-658113-19)

16 American Diabetes Association. Standards of medical care in diabetes 2019. Diabetes Care 201942 (Supplement 1) S34-S45. (https://doi. org/10.2337/dc19-S004)

17 American Association of Clinical Endocrinologists and American College of Endocrinology. Clinical practice guidelines for developing a diabetes mellitus comprehensive care plan. Endocrinepractice 2015 21(Supplement 1 April) 1.

18 Owhin SO, Adaja TM, Fasipe OJ, Akhideno PE, Kalejaiye OO \& Kehinde MO. Prevalence of vitamin B12 deficiency among metformin-treated type 2 diabetic patients in a tertiary institution, South-South Nigeria. SAGE Open Medicine 20197 2050312119853433. (https://doi.org/10.1177/2050312119853433)

19 Raizada N, Jyotsna VP, Sreenivas V \& Tandon N. Serum vitamin B12 levels in Type 2 diabetes patients on metformin compared to those never on metformin: a cross-sectional study. Indian Journal of Endocrinology \& Metabolism 201721 424-428. (https://doi. org/10.4103/ijem.IJEM_529_16)

20 Beulens JW, Hart HE, Kuijs R, Kooijman-Buiting AM \& Rutten GE. Influence of duration and dose of metformin on cobalamin deficiency in type 2 diabetes patients using metformin. Acta Diabetologica 201552 47-53. (https://doi.org/10.1007/s00592-0140597-8)

21 Ahmed MA, Muntingh G \& Rheeder P. Vitamin B12 deficiency in metformin-treated type- 2 diabetes patients, prevalence and association with peripheral neuropathy. BMC Pharmacology \& Toxicology 201617 44. (https://doi.org/10.1186/ s40360-016-0088-3)

22 Yang W, Cai X, Wu H \& Ji L. Associations between metformin use and vitamin B12 levels, anemia, and neuropathy in patients with diabetes: a meta-analysis. Journal of Diabetes 201911 729-743. (https://doi.org/10.1111/1753-0407.12900)

23 Nervo M, Lubini A, Raimundo FV, Faulhaber GA, Leite C, Fischer LM \& Furlanetto TW. Vitamin B12 in metformin-treated diabetic patients: a cross-sectional study in Brazil. Revista da Associação
Médica Brasileira 201157 46-49. (https://doi.org/10.1016/S22554823(11)70015-7)

24 Ting RZ, Szeto CC, Chan MH, Ma KK \& Chow KM. Risk factors of vitamin B(12) deficiency in patients receiving metformin. Archives of Internal Medicine 2006166 1975-1979. (https://doi.org/10.1001/ archinte.166.18.1975)

25 Iqbal Z, Azmi S, Yadav R, Ferdousi M, Kumar M, Cuthbertson DJ, Lim J, Malik RA \& Alam U. Diabetic peripheral neuropathy: epidemiology, diagnosis, and pharmacotherapy. Clinical Therapeutics 201840 828-849. (https://doi.org/10.1016/j.clinthera.2018.04.001)

26 Khawaja N, Abu-Shennar J, Saleh M, Dahbour SS, Khader YS \& Ajlouni KM. The prevalence and risk factors of peripheral neuropathy among patients with type 2 diabetes mellitus; the case of Jordan. Diabetology \& Metabolic Syndrome 201810 8. (https://doi. org/10.1186/s13098-018-0309-6)

27 Gupta K, Jain A \& Rohatgi A. An observational study of vitamin B12 levels and peripheral neuropathy profile in patients of diabetes mellitus on metformin therapy. Diabetes and Metabolic Syndrome 2018 12 51-58. (https://doi.org/10.1016/j.dsx.2017.08.014)

28 Alharbi TJ, Tourkmani AM, Abdelhay O, Alkhashan HI, Al-Asmari AK, Bin Rsheed AM, Abuhaimed SN, Mohammed N, AlRasheed AN \& AlHarbi NG. The association of metformin use with vitamin B12 deficiency and peripheral neuropathy in Saudi individuals with type 2 diabetes mellitus. PLOS ONE 201813 e0204420. (https://doi. org/10.1371/journal.pone.0204420)

29 Sun Y, Lai MS \& Lu CJ.Sun. Effectiveness of vitamin B12 on diabetic neuropathy: systematic review of clinical controlled trials. Acta Neurologica Taiwanica 200514 48-54.

30 Zalaket J, Wehbe T \& Abou Jaoude E. Vitamin B12 deficiency in diabetic subjects taking metformin: a cross sectional study in a Lebanese cohort. Journal of Nutrition \& Intermediary Metabolism 2018 11 9-13. (https://doi.org/10.1016/j.jnim.2017.12.001)

31 Jayabalan B \& Low LL. Vitamin B supplementation for diabetic peripheral neuropathy. Singapore Medical Journal 201657 55-59. (https://doi.org/10.11622/smedj.2016027)

32 Mottaghi T, Khorvash F, Maracy M, Bellissimo N \& Askari G. Effect of folic acid supplementation on nerve conduction velocity in diabetic polyneuropathy patients. Neurological Research 201941 364-368. (https://doi.org/10.1080/01616412.2019.1565180)

Received in final form 8 September 2019

Accepted 13 September 2019

Accepted Preprint published online 13 September 2019 https://ec.bioscientifica.com https://doi.org/10.1530/EC-19-0382 (c) 2019 The authors Published by Bioscientifica Ltd
This work is licensed under a Creative Commons Attribution-NonCommercial-NoDerivatives 4.0 Anternationab sicense ifica com at 04/26/2023 09:23:12AM 